\title{
A Rare Case Report of Deep Vein Thrombocytosis associated with Brucellosis in Iran
}

\author{
Majid Ghafouri ${ }^{1}$, Mojtaba Danafar ${ }^{1}$, and Azar Shokri ${ }^{1}$ \\ ${ }^{1}$ North Khorasan University of Medical Sciences
}

September 25, 2021

\author{
Abstract \\ Brucellosis is among the most prevalent zoonotic diseases that can involve almost any organ. Here we present a case of deep vein \\ thrombosis due to human brucellosis. We described a 62 old male farmer with a history of brucellosis and deep vein thrombosis \\ on his right leg \\ A Rare Case Report of Deep Vein Thrombocytosis associated with Brucellosis in Iran \\ Majid Ghafouri ${ }^{1,3}$, Mojtaba Danafar ${ }^{2}$, Azar Shokri *1 \\ ${ }^{1}$ Vector-borne Diseases Research Center, North Khorasan University of Medical Sciences, Bojnurd, Iran \\ Email: M.Ghafouri@nkums.ac.ir \\ ${ }^{2}$ Student Research Committee, North Khorasan University of Medical Sciences, Bojnurd, Iran \\ Email: mojtaba.danafar@gmail.com \\ *Correspond author: \\ Email: azar_sh1969@yahoo.com
}

Key clinical message

Deep vein thrombosis should be considered in any patient with a history of brucellosis. It is an important point in brucellosis endemic regions.

\section{Abstract}

Brucellosis is among the most prevalent zoonotic diseases that can involve almost any organ. Here we present a case of deep vein thrombosis due to human brucellosis. We described a 62 old male farmer with a history of brucellosis and deep vein thrombosis on his right leg.

Key words : Deep vein thrombosis, Brucellosis, Iran

\section{INTRODUCTION}

Brucellosis is a cosmopolitan zoonotic disease that mainly affects persons with close contact with domestic animals and their products [1]. The infection is caused by Gram negative intracellular, non-motile, nonsporulating, nontoxigenic, non-fermenting, facultative cocco-bacilli bacteria of genus Brocella with over than ten species. The disease is endemic in many countries including Iran and the incidence of the disease is estimated to be 500,000 cases annually all around the world [2]. Brucellosis is a multi-systemic disease with a broad spectrum of clinical manifestations and, can be potentially lethal due to complications [3]. Despite of 
common osteoarticular complication in endemic regions, the vascular complication is almost rare [4]. Hereby we describe a case of deep vein thrombosis (DVT) in Bojnurd, North east of Iran.

\section{CASE REPORT}

A 62 old male farmer, with a history of brucellosis in last two months referred to our hospital. His main complaint was pain and swelling of right calf muscle. His symptoms started with irregular fever, dyspnea and malaise two months earlier. He was treated for brucellosis with Rifampin, Cotrimoxazole and Doxycycline, and after one week break in medication, his shin started swelling. He had no history of brucelloisi in his family. Also, he claimed to opium addiction. Laboratory tests were asked for further evaluation. In physical examination, his legs were asymmetric and the left shin obviously was larger than right one. The rest of the physical examinations were normal. The patient underwent to Doppler ultrasonography (Image 1).

\section{DIFFERENTIAL DIAGNOSIS, INVESTIGATIONS AND TREATMENTS}

Complete blood count and biochemical parameters were within normal range. $5.1 \times 10^{12} / \mathrm{L}$, hemoglobin $14.3 \mathrm{~g} / \mathrm{L}$, white blood cells $12.5 \times 109 / \mathrm{L}$ (65\% neutrophils). Erythrocyte sedimentation rate (ESR) was 20 $\mathrm{mm} / \mathrm{h}$. C reactive protein $(\mathrm{CRP})$ was positive $(+2)$. All laboratory parameters including protein C\&S, Anti Phospholipid antibodies (IgM, IgG), Anti Cardiolipin antibodies (IgM, IgG), Anti lupus Anti-Coagulant IgG, Factor V Leiden and Prothrombin G20210A (Factor II) were within normal range. The tubal standard agglutination test (Wright test) and 2ME reduction test were positive (in a titer of 1/1280 and 1/640, respectively). A Doppler ultrasound study revealed right popliteal vein thrombosis (Figures 1, 2). There was no effusion in sonographic evaluation of right hip joint. Subcutaneous soft tissue edema in right lower extremity was reported. The patient was diagnosed with thrombophlebitis due to brucellosis. He was advised to have bed rest and right leg elevation. The patient was treated with Rifampicin $300 \mathrm{mg}$ twice a day, Cotrimoxazole $800 \mathrm{mg}$ twice day, Azithromycin $200 \mathrm{mg}$ once a day and two days later Rivaroxaban $15 \mathrm{mg}$ twice a day for the first three weeks and $20 \mathrm{mg}$ once a day. Also, Enoxaparin 60-unit S.C twice a day was prescribed. Some days later, his leg pain and swelling decreased and he walked without any help. Nine days after the onset of this treatment, thrombophlebitis was cured. Warfarin was discontinued after six months. Follow up of the patient showed no abnormality after approximately one year later.

\section{DISCUSSION}

Brucellosis is among the most prevalent zoonotic diseases all around the world including. Iran is an endemic region for disease and the annual incidence rate of human and animal infection is still considerable [2]. Deep vein thrombosis is a rare complication of brucellosis and its pathogenesis has not been described well $[5,6]$. The probable mechanisms are including the occurrence of granulomatous endophlebitis, inflammation and injury of perivascular tissue, a transient hypercoagulable state, or the immune reaction in the vessel wall to the brucella antigen [7]. Nine reports are available from 1973 to 2012 which are describing deep vein thrombosis associated with brucellosis in endemic regions [8,9]. Protein S deficiency with DVT was observed during infection with Salmonella typhimurium, and HIV infection [10,11]. In our patient anti Phospholipid antibodies, anti Cardiolipin antibodies, anti-lupus anti-Coagulant IgG, Factor V Leiden and Prothrombin G20210A (Factor II) were normal. Also, local infection adjacent to his right leg deep veins was not observed during his illness. Therefore, it is possible that endothelial damage induced directly by Brucella, or indirectly by toxins or cytokines, was responsible for the patient's DVT.CONCLUSIONS: Due to the non-specific manifestations of acute brucellosis, it is suggested that the infection should be considered in patients suffering from DVT, particularly in those coming from Brucellosis-endemic areas.ACKNOWLEDGMENTS: The authors thank Clinical Research Development Unit, Imam Hasan Hospital, North Khorasan University of Medical Sciences, Bojnurd, Iran. CONFLICT OF INTEREST: None declared.AUTHOR'S CONTRIBUTIONS: All authors, M Gh, M D and A Sh are equally contributed to the design, analysis, and presentation of this study M Ghis specialist in infectious disease and involved in study design. M D: involved in study design and writing. A Sh: Involved in study design, writing, submission and revisionDECLARATIONEthics approval and consent to participate: applicable -Consent for publication: Written informed consent was obtained from the patient for publication of this case report and any accompanying images. A copy of 
the written consent is available for review by the Editor of this journal. -Availability of data and material: All the data are available without restriction. -Funding: No funding.

References

1. Salih Salihi1, Şeyda Andaç2, Mehmet Kalender3, Onur Yıldırım2, Ayfer İmre. Simultaneous acute deep vein thrombosis and acute brucellosis. A case report. Kardiochirurgia i Torakochirurgia Polska 2016; 13 (2)

2. Golshani M, Buozari S. A Review of Brucellosis in Iran: Epidemiology, Risk Factors, Diagnosis, Control, and Prevention. Iranian Biomedical Journal 2017:21(6): 349-359

3. Tolaj I, Mehmeti M, Ramadani H, Dedushi K, Fejza H. Brucellosis associated with deep vein thrombosis. Infectious Disease Reports 2014; 6:5441

4. Davoudi AR, Tayebi A, Najafi N, Kasiri E. Deep vein thrombosis as a rare complication of brucellosis. Caspian Journal of Internal Medicine 2014; 5(2): 127-129

5. Colmenero JD, Reguera JM, Martos J et al. Complications associated with Brucella melitensis infection: a study of 530 cases. Medicine 1996; 79: 195-211.

6. Andrew WK. An unusual cause of deep venous thrombosis of the lower limb. S Afr Med J 2000; 90: 42.

7. Memish Z. A., Bannatyne R. M, Alshaalan M. Endophlebitis of the Leg Caused by Brucella Infection. The British Infection Society. doi:10.1053/jinf. 2001.0794

8. Koubaa M, Frigui M, Cherif Y, et al. Deep vein thrombosis associated with acute brucellosis: a case report and review of the literature. Korean J Intern Med. 2013; 28: 628-30.

9. Odeh M, Pick N, Oliven A. Deep venous thrombosis associated with acute brucellosis-a case report. Angiology. 2000; 51: 253-6.

10. Ceyhan M, Kanra G, Benderlioglu B, et al: Transient protein S deficiency with deep venous thrombosis during Salmonella typhimurium infection. Arch Dis Child 68:138-139, 1993.

11. Becer DM, Saunders TJ, Wispelwey B, et al: Case report: Venous thromboembolism in AIDS. Am J Med Sci 303:395-397, 1992

\section{Hosted file}

Image.docx available at https://authorea.com/users/370332/articles/539131-a-rare-casereport-of-deep-vein-thrombocytosis-associated-with-brucellosis-in-iran 